\title{
Nasal epidermoid cyst with sinus tract
}

\author{
Vivek Kalra $\cdot$ Ajay Malhotra
}

Received: 12 November 2009/Revised: 10 December 2009/Accepted: 30 December 2009/Published online: 13 February 2010

(C) Springer-Verlag 2010

A 2-year-old girl underwent MRI evaluation of a prominent nasal bridge. A $1.0 \times 0.6-\mathrm{cm}$ midline nonenhancing lesion was seen embedded in the nasal bone that was isointense to gray matter on T2-W (Fig. 1, large arrow) images and demonstrated restricted diffusion (Fig. 2, arrow). There was a linear sinus tract extending from the lesion to the floor of the anterior cranial fossa (Fig. 1, small arrow). These findings are suggestive of a nasal epidermoid cyst.

Differentials include nasal dermal sinus, anterior cephalocele, and nasal glioma [1]. Nasal dermoid and epidermoid cysts result from congenital failure of involution of the anterior neuropore and are best evaluated with MRI. Epidermoid cysts have less $\mathrm{T} 1$ shortening than dermoid cysts, which contain fat in addition to desquamated epithe-

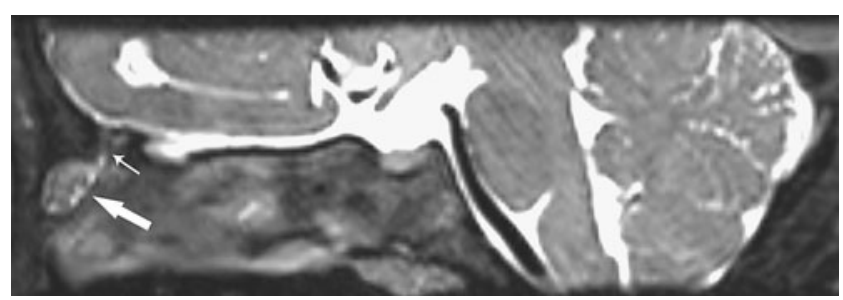

Fig. 1 Mid-sagittal T2-W image

V. Kalra $(\bowtie) \cdot$ A. Malhotra Diagnostic Radiology, Yale University,

111 Park St., Apt. 2J,

New Haven, CT 06511, USA

e-mail: kalramd@gmail.com

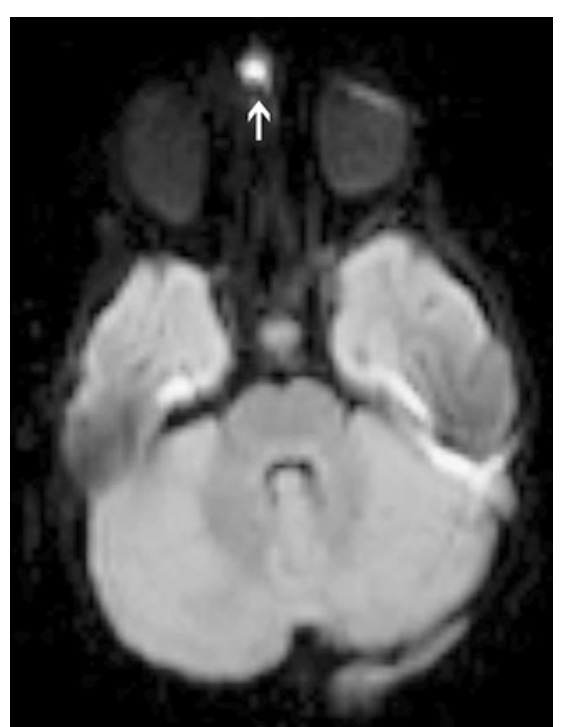

Fig. 2 Diffusion-weighted image

lium. Epidermoid cysts, with epithelial cells' tendency to grow in layers, have increased restricted diffusion compared to dermoid cysts [2]. Surgical resection is warranted given the potential complications of osteomyelitis and meningitis.

\section{References}

1. Hedlund G (2006) Congenital frontonasal masses: developmental anatomy, malformations, and MR imaging. Pediatr Radiol 36:647662

2. Bergui M, Zhong J, Bradac GB et al (2001) Diffusion-weighted images of intracranial cyst-like lesions. Neuroradiology 43:824829 